\title{
Sustained Tau Phosphorylation and Microglial Activation Following Repetitive Traumatic Brain Injury
}

\author{
Andre Marolop Pangihutan Siahaan ${ }^{1 *}$, Rr Suzy Indharty ${ }^{1}$, Jessy Chrestella ${ }^{2}$, Wismaji Sadewo ${ }^{3}$, Steven Tandean $^{1}$, Siti Syarifah $^{4}$ \\ ${ }^{1}$ Department of Neurosurgery, Faculty of Medicine, Universitas Sumatera Utara, Medan, Indonesia; ${ }^{2}$ Department of Anatomic \\ Pathology, Faculty of Medicine, Universitas Sumatera Utara, Medan, Indonesia; ${ }^{3}$ Department of Neurosurgery, Faculty of \\ Medicine, Universitas Indonesia, Jakarta, Indonesia; ${ }^{4}$ Department of Pharmacology and Therapeutic, Faculty of Medicine, \\ Universitas Sumatera Utara, Medan, Indonesia
}

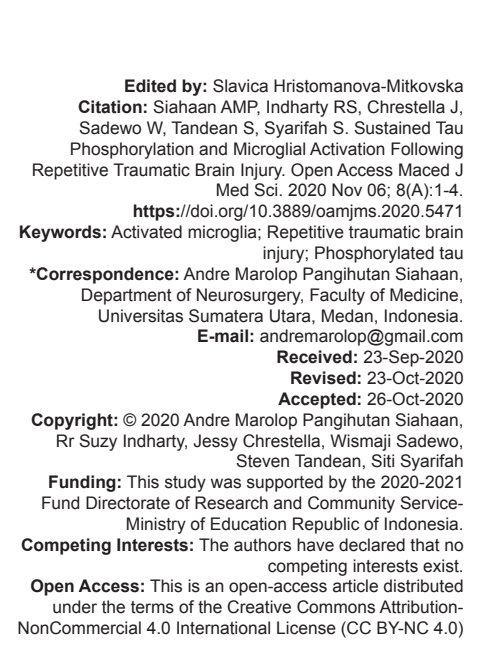

\section{Abstract}

BACKGROUND: Repetitive traumatic brain injury (TBI), even without acute sequela, can induce a delayed neurodegenerative with overexpression of phosphorylated tau ( $\mathrm{p}$-tau) as hallmark, caused by chronic inflammation mediated in part by microglial activation.

AIM: The aim of this study was to examine the dynamics of p-tau accumulation and microglial activation following repetitive TBI.

MATERIALS AND METHODS: Thirty Sprague-Dawley rats were randomized into a sham control group and two treatment groups receiving three successive closed-skull impacts (TBI model) from a 40-g mass dropped from a 1-m height on alternating days (days $0,1,3$, and 7 ). The first treatment group was sacrificed on the last day of trauma and the second treatment group after 7 days of no trauma. The expression level of p-tau was evaluated by AT- 8 antibody immunostaining and microglial activation by anti-CD-68 immunostaining.

RESULTS: Immunoexpression of AT- 8 was significantly elevated 7 days after TBI compared to the last day of trauma and compared to the sham control group, while CD-68 expression was significantly higher than sham controls on the last day of trauma and remained elevated for 7 days without trauma.

CONCLUSION: The study showed that brain trauma can induce p-tau overexpression and microglial activation that is sustained during the non-trauma period.

\section{Introduction}

Traumatic brain injury (TBI) is a wellknown risk factor for neurodegenerative disease independent of age. In a large-scale study involving 44,925 patients with a history of TBI, Wang et al. (2012) reported a $60 \%$ increase in dementia incidence [1]. The same finding was reported by Barnes et al. (2014) in a study of 188,674 veterans, where $\mathrm{TBI}$ increased dementia incidence by up to $60 \%$ [2].

Accumulation of phosphorylated tau ( $p$-tau) is thought to be the main driver of neurodegeneration following TBI [3], [4]. Repetitive TBI can induce a constellation of clinical manifestations such as cognitive deficits, mood instability, and behavioral abnormalities associated with the accumulation of p-tau and TDP-43 [5], [6]. This degenerative changed, namely Chronic Traumatic Encephalopathy, has gained much attention recently due to reports that some relatively young American football players have developed these clinical manifestations and that brain pathology at autopsy has found changes consistent with early-onset dementia [7].

Under physiological conditions, tau protein is crucial for maintaining microtubule stability [8]. Repeated TBI may activate protein tau kinases, leading to the accumulation of p-tau [9], and microglial activation is one potential cause of tau kinase activation [10]. There are two potential causes of progressive neurodegenerative disease following TBI. First, microglial activation may sustain chronic neuroinflammation; indeed, activated microglia have been detected even years following TBI [11]. Second, p-tau is a prion that can be propagated into surrounding cells [12]. Based on these pathogenic mechanisms, the aim of this study was to explore the dynamics of p-tau and activated microglia after a rest period with no trauma following repetitive TBI. 


\section{Materials and Methods}

\section{Animal model and experimental groups}

Thirty Sprague-Dawley rats (6-8 weeks old and weighing 300-350 g) were randomized into three groups, a sham control group and two treatment groups. The animals were maintained in a temperature-controlled room at $22-24^{\circ} \mathrm{C}$ under a 12 h-12 h dark-light cycle with ad libitum access to food and water. Animals were housed under these conditions for 7 days for adaptation before experiments and following TBI.

For induction of TBI, a 40-g mass was dropped onto the cranial vertex from a 1-m height. To prevent skull fracture, a metal helmet of $2.5-\mathrm{cm}$ diameter was placed on the vertex. Each treatment group rat was subjected to 3 impacts on alternating days (days $0,1,3$, and 7 ) with rest periods on days $2,4,5$, and 6. No anesthesia was used in this protocol [13]. The first trauma group was sacrificed on day 7 soon after the last $\left(12^{\text {th }}\right)$ impact, while the second trauma group was sacrificed 7 days after the last impact without intervening treatment or TBI. This procedure was approved by the Medical Research Ethics Committee of the Medical Faculty, Universitas Sumatera Utara (Medan, Indonesia).

\section{Brain isolation}

Rats were anesthetized with ether and decapitated. The skull was cut from the foramen magnum to the anterior pole on the left and right sides and the olfactory bulb discarded. The remaining whole brain was fixed in $10 \%$ formalin buffer $(10 \%)$.

\section{Immunohistochemistry}

p-tau was detected using the AT-8 antibody (Thermo Fisher) and activated microglial using anti-CD-68 (Thermo Fisher). Briefly, brain tissue was embedded in paraffin and cut into 4- $\mu \mathrm{m}$ thick sections, including the cortex under the vertex. For examination of immunoreactivity, cells were counted in 20 randomly chosen fields at $400 \times$ magnification.

\section{Statistical Analysis}

All results are expressed as mean \pm SEM. Group means were compared by analysis of variance with Tukey's post tests for pair-wise comparisons or by independent samples t-test. $p<0.05$ (two-tailed) was considered statistically significant.

\section{Results}

\section{Repetitive traumatic brain injuries caused sustained microglial activation}

Trauma Group 1 exhibited an increased number of CD-68+ cells and greater immunostaining intensity compared to the sham control group (Figure 1a and 1b). After 7 days with no TBI, CD-68 expression was still higher in trauma Group 2 than the sham control group, although the staining intensity was reduced compared to immediately after TBI. However, the number of CD-68+ cells did not differ between trauma Groups 1 and 2 (Figure 1b and 1c).

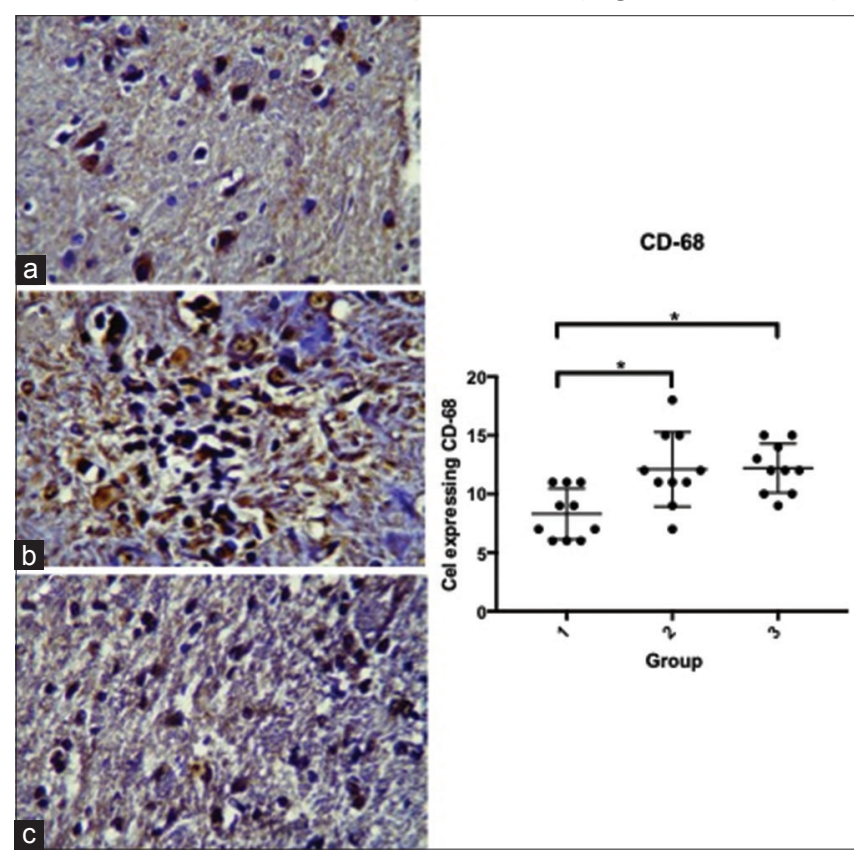

Figure 1: $C D-68$ expression in cortical brain slices from the sham control group (a), treatment Group 1 (b), and treatment Group 2 (c). Expression was significantly elevated in the treatment groups compared to the sham control group $\left({ }^{*} p<0.05\right.$ by one-way ANOVA with post hoc Tukey tests), indicating sustained microglial activation following TBI. Group 1: Sham control group; Group 2: Trauma 1; Group 3: Trauma 2. Data are expressed as mean \pm SEM

\section{Repetitive traumatic brain injuries caused prolonged tau phosphorylation}

Immunoexpression of $\mathrm{p}$-tau was also significantly enhanced in trauma Group 1 compared to the sham control group (Figure $2 a$ and $2 b$ ). Further, expression was even higher after 1 week without TBI (Figure 2c).

\section{Discussion}

Hyperphosphorylation of tau protein is the hallmark of the neurodegenerative disorder induced 


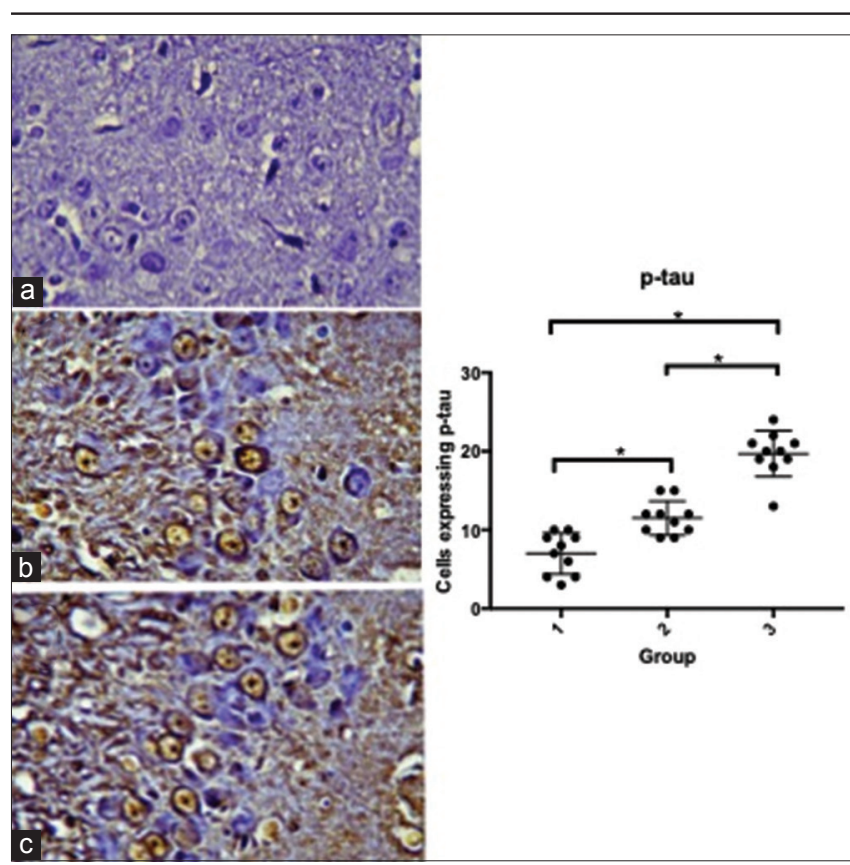

Figure 2: Expression of phosphorylated tau in cortical brain slices from the sham control group (a), treatment Group 1 (b) and treatment Group 2 (c). Expression was highest in treatment Group $2\left({ }^{*} p<0.05\right.$ by one-way ANOVA with post hoc Tukey test). Group 1: Sham control group; Group 2: Trauma 1; Group 3: Trauma 2. Data are expressed as mean \pm SEM

by repetitive TBI [14]. Although it is still debated, there is growing evidence that $\mathrm{p}$-tau accumulated following TBI will aggregate to form oligomers and ultimately neurotoxic neurofibrillary tangles [9]. In this study, same as the model we used, we found an increase of p-tau expression following repetitive TBIs [13].

The mechanism mediating TBI-induced phosphorylation and aggregation of tau protein is still uncertain, but microglial activation and ensuing neuroinflammation are strongly implicated [15], [16]. Indeed, activated microglia were observed before tau pathology in an animal model of tauopathy [17] and Maphis et al. (2015) report that reactive microglia are sufficient to drive tau pathology in an animal model of AD [18].

TBI will induce a complex inflammatory response involving proliferation and migration of resident microglia to the site of injury. Microglia then becomes activated and transforms to amoeboidlike cells that secrete pro-inflammatory or antiinflammatory cytokines. Pro-inflammatory cytokines promote phagocytic activity and host defense, while anti-inflammatory cytokines promote repair and remodeling [19].

Chronic neuroinflammation has been observed following both moderate and severe head injury. Johnson et al. (2013) reported persistent inflammation and white matter degeneration years after single TBI [20]. Mild head injury itself may induce axonal disruption that, in turn, triggers a neuroinflammatory response to repair or limit the damage [21]. Following a single mild head injury, this response will dissipate as the brain is repaired. However, repetitive TBI within a short interval induces a persistent pro-inflammatory state [22]. In this research, we demonstrated such a persistent inflammatory response after a week without TBI, as evidenced by a sustained increase in CD-68+ cells and a continued increase in p-tau expression.

Neuroinflammation also drives hyperphosphorylation of tau protein. In this study, there was a significant increase in AT-8 immunostaining during the rest period. This continued p-tau accumulation may result from persistent microglial activation. Alternatively, p-tau accumulation may become selfperpetuating through prion activity [23]. Tau may interact with the cell membrane to facilitate prion-like propagation, followed by uptake into recipient cells via macropinocytosis [24]. Although phosphorylation is reversible, tau seeding and propagation could promote further neurodegeneration [25].

The main limitation of this study is that AT-8 and CD-68 expression were not localized to specific cell types using double immunolabeling. Similarly, microglia polarization was not directly examined. Finally, the TBI-free period should be extended to better model repeated TBI in humans.

\section{Conclusion}

The repeated TBI-induced sustained microglial activation during the ensuing $\mathrm{TBI}$-free period and a continued increase in $\mathrm{p}$-tau expression. These sustained changes may account for the progressive nature of neurodegeneration during repeated TBI.

\section{Acknowledgment}

This study was funded by the 2020-2021 Fund Directorate of Research and Community ServiceMinistry of Education Republic of Indonesia. We thank Wibi Riawan (Universitas Brawijaya, Malang, Indonesia) for helping in conducting the trauma. We thank Iskandar Japardi (Universitas Sumatera Utara, Medan, Indonesia) for comments on the manuscript.

\section{References}

1. Wang HK, Lin SH, Sung PS, Wu MH, Hung KW, Wang LC, et al. Population based study on patients with traumatic brain injury suggests increased risk of dementia. J Neurol Neurosurg 
Psychiatry. 2012;83(11):1080-5. https://doi.org/10.1136/ jnnp-2012-302633

PMid:22842203

2. Barnes DE, Kaup A, Kirby KA, Byers AL, Diaz-Arrastia $R$, Yaffe K. Traumatic brain injury and risk of dementia in older veterans. Neurology. 2014;83(4):312-9. https://doi.org/10.1212/ wnl.0000000000000616

PMid:24966406

3. Hawkins BE, Krishnamurthy S, Castillo-Carranza DL, Sengupta U, Prough DS, Jackson GR, et al. Rapid accumulation of endogenous tau oligomers in a rat model of traumatic brain injury: Possible link between traumatic brain injury and sporadic tauopathies. J Biol Chem. 2013;288(23):17042-50. https://doi. org/10.1074/jbc.m113.472746

PMid:23632019

4. Johnson VE, Stewart W, Smith DH. Traumatic brain injury and amyloid- $\beta$ pathology: A link to Alzheimer's disease? Nat Rev Neurosci. 2010;11(5):361-70. https://doi.org/10.1038/nrn2808 PMid:20216546

5. McKee AC, Cairns NJ, Dickson DW, Folkerth RD, Keene CD Litvan I, et al. The first NINDS/NIBIB consensus meeting to define neuropathological criteria for the diagnosis of chronic traumatic encephalopathy. Acta Neuropathol. 2017;131(1):7586. https://doi.org/10.1007/s00401-015-1515-z

PMid:26667418

6. Montenigro PH, Bernick C, Cantu RC. Clinical Features of Repetitive Traumatic Brain Injury and Chronic Traumatic Encephalopathy. Brain Pathol. 2015;25(3):304-17. https://doi. org/10.1111/bpa.12250

PMid:25904046

7. Omalu B. Chronic traumatic encephalopathy. Prog Neurol Surg. 2014;28:38-49.

PMid:24923391

8. Morris M, Maeda S, Vossel K, Mucke L. The many faces of tau. Neuron. 2011;70(3):410-26. https://doi.org/10.1016/j. neuron.2011.04.009

PMid:21555069

9. Lucke-Wold BP, Turner RC, Logsdon AF, Bailes JE, Huber JD, Rosen CL. Linking traumatic brain injury to chronic traumatic encephalopathy: Identification of potential mechanisms leading to neurofibrillary tangle development. J Neurotrauma 2014;31(13):1129-38. https://doi.org/10.1089/neu.2013.3303 PMid:24499307

10. Loane DJ, Kumar A. Microglia in the TBI brain: The good, the bad, and the dysregulated. Exp Neurol. 2016;275 Pt 3(0 3):31627. https://doi.org/10.1016/j.expneurol.2015.08.018 PMid:26342753

11. Loane DJ, Kumar A, Stoica BA, Cabatbat R, Faden Al. Progressive neurodegeneration after experimental brain trauma: Association with chronic microglial activation. J Neuropathol Exp Neurol. 2014;73(1):14-29. https://doi.org/10.1097/ nen.0000000000000021 PMid:24335533

12. De Calignon $A$, Polydoro $M$, Suárez-Calvet $M$, William $C$ Adamowicz DH, Kopeikina KJ, et al. Propagation of tau pathology in a model of early Alzheimer's disease. Neuron. 2012;73(4):68597. https://doi.org/10.1016/j.neuron.2011.11.033 PMid:22365544

13. $\mathrm{Xu} \mathrm{L,} \mathrm{Nguyen} \mathrm{JV,} \mathrm{Lehar} \mathrm{M,} \mathrm{Menon} \mathrm{A,} \mathrm{Rha} \mathrm{E,} \mathrm{Arena} \mathrm{J,} \mathrm{et} \mathrm{al.}$ Repetitive mild traumatic brain injury with impact acceleration in the mouse: Multifocal axonopathy, neuroinflammation, and neurodegeneration in the visual system. Exp Neurol. 2016;275:43649. https://doi.org/10.1016/j.expneurol.2014.11.004

\section{PMid:25450468}

14. McKee AC, Stein TD, Nowinski CJ, Stern RA, Daneshvar DH, Alvarez VE, et al. The spectrum of disease in chronic traumatic encephalopathy. Brain. 2013;136(1):43-64.

PMid:23208308

15. Cherry JD, Tripodis Y, Alvarez VE, Huber B, Kiernan PT, Daneshvar $\mathrm{DH}$, et al. Microglial neuroinflammation contributes to tau accumulation in chronic traumatic encephalopathy. Acta Neuropathol Commun. 2016;4:112. https://doi.org/10.1186/ s40478-016-0382-8

PMid:27793189

16. Collins-Praino LE, Corrigan F. Does neuroinflammation drive the relationship between tau hyperphosphorylation and dementia development following traumatic brain injury? Brain Behav Immun. 2017:60:369-82. https://doi.org/10.1016/j. bbi.2016.09.027

PMid:27686843

17. Yoshiyama Y, Higuchi M, Zhang B, Huang S-M, Iwata N, Saido TC et al. Synapse loss and microglial activation precede tangles in a P301S tauopathy mouse model. Neuron. 2007;53(3):337-51. https://doi.org/10.1016/j.neuron.2007.01.010

PMid: 17270732

18. Maphis N, Xu G, Kokiko-Cochran ON, Jiang S, Cardona A Ransohoff RM, et al. Reactive microglia drive tau pathology and contribute to the spreading of pathological tau in the brain. Brain. 2015;138(6):1738-55. https://doi.org/10.1093/brain/awv081 PMid:25833819

19. Simon DW, McGeachy MJ, Bayır H, Clark RSB, Loane DJ, Kochanek PM. The far-reaching scope of neuroinflammation after traumatic brain injury. Nat Rev Neurol. 2017;13(3):171-91. https://doi.org/10.1038/nrneurol.2017.13 PMid:28186177

20. Johnson VE, Stewart JE, Begbie FD, Trojanowski JQ, Smith DH, Stewart W. Inflammation and white matter degeneration persist for years after a single traumatic brain injury. Brain. 2013;136(1):28-42. https://doi.org/10.1093/brain/aws322 PMid:23365092

21. Shitaka Y, Tran HT, Bennett RE, Sanchez L, Levy MA, Dikranian $\mathrm{K}$, et al. Repetitive closed-skull traumatic brain injury in mice causes persistent multifocal axonal injury and microglial reactivity. J Neuropathol Exp Neurol. 2011;70(7):551-67. https:// doi.org/10.1097/nen.0b013e31821f891f PMid:21666502

22. Blennow K, Brody DL, Kochanek PM, Levin H, McKee A, Ribbers GM, et al. Traumatic brain injuries. Nat Rev Dis Primers. 2016;2:16084. https://doi.org/10.1038/nrdp.2016.84 PMid:27853132

23. Prusiner SB. Novel proteinaceous infectious particles cause scrapie. Science. 1982;216(4542):136-44. https://doi. org/10.1126/science.6801762

PMid:6801762

24. Kriegel J, Papadopoulos Z, McKee AC. Chronic traumatic encephalopathy: Is latency in symptom onset explained by tau propagation? Cold Spring Harb Perspect Med. 2018;8(2):a024059. https://doi.org/10.1101/cshperspect. a024059

\section{PMid:28096246}

25. Van der Jeugd A, Hochgräfe K, Ahmed T, Decker JM, Sydow A Hofmann $A$, et al. Cognitive defects are reversible in inducible mice expressing pro-aggregant full-length human tau. Acta Neuropathol. 2012;123(6):787-805. https://doi.org/10.1007/ s00401-012-0987-3

PMid:22532069 